\title{
THE FREEZING POINT OF NICKEL AS A FIXED POINT ON THE INTERNATIONAL TEMPERATURE SCALE
}

\author{
By H. T. Wensel and Wm. F. Roeser
}

\section{ABSTRACT}

The freezing point of nickel was determined by measuring with an optical pyromcter the ratio of brightness of red light of wave length $0.6533 \mu$ emitted by black bodies at the freezing points of nickel and gold, respectively. The nickel was frozen in magnesia crucibles in vacuo. The freezing point was found to be $1,455^{\circ} \mathrm{C}$. on the International Temperature Scale with an uncertainty of $1^{\circ}$, based on the value $1,063^{\circ} \mathrm{C}$. for the freezing point of gold and $1,432 \mathrm{~cm} \mathrm{deg}$. for

The temperature coefficient af resistance of the two separate ingots of nickel used was approximately 0.0067 in the interval $0^{\circ}$ to $100^{\circ} \mathrm{C}$. The chemical analyses indicated the purity of the nickel as 99.94 per cent.

The importance of the nickel point in optical pyrometry is discussed. The freezing point of pure nickel in magnesia crucibles was found to be very satisfactory as a fixed point in accurately extending the high-temperature scale beyond the platinum point.

\section{CONTENTS}

I. Introduction

II. Previous work

III. Purity of nickel

IV. Experimental work and results

V. Discussion

\section{INTRODUCTION}

From the standpoint of optical pyrometry, the freezing point of nickel occupies a unique place on the temperature scale. The location of this point is such that it may be very usefully employed as a starting point in fundamental work in optical pyrometry at very high temperatures. The manner in which the nickel point can be used and the reason for its importance will appear from a brief description of the procedure followed in measuring such temperatures.

On the International Temperature Scale, ${ }^{1}$ adopted in 1927, the temperature $t$ of a black body above $1,063^{\circ} \mathrm{C}$. or $1,336^{\circ} \mathrm{K}$. (the freezing point of pure gold) is defined by the formula

$$
\log _{\epsilon} R=\log _{\epsilon} \frac{J}{J_{1}}=\frac{1.432}{\lambda}\left(\frac{1}{1,336}-\frac{1}{t+273}\right)
$$

whence

$$
\frac{1}{t+273}=\frac{1}{1,336}-\frac{\lambda \log _{e} R}{1.432}
$$


In this formula $J_{1}$ is the intensity of monochromatic visible radiation of wave length $\lambda \mathrm{cm}$ emitted by a black body at the gold point and $J$ is the intensity of radiation of the same wave length emitted by a black body at temperature $t^{\circ} \mathrm{C}$.

In principle, the procedure followed in determining the temperature of a black body is as follows: An optical pyrometer is sighted into a black body at the melting or freezing point of gold. This black body may be either a furnace in which is mounted a thermocouple with a bit of gold welded between the hot junction ends (wire method) or preferably a hollow inclosure or sight tube immersed in a crucible of melting or freezing gold (crucible method). The current which must be sent through the pyrometer lamp to secure a brightness match in the field of view is determined. When operating at this current, the lamp is said to be operating "at the gold point" although the actual temperature of the filament may not be $1,063^{\circ} \mathrm{C}$. The optical pyrometer is next sighted into the black body at temperature $t$ and, still operating the lamp at the gold point, an absorption device of known transmission is introduced which will reduce the light from the black body to the proper intensity to again produce a photometric match. The reciprocal of the transmission of the absorption device may then be substituted for $R$ in equation (2). If a spectral pyrometer is used the value of $\lambda$ may be obtained from the monochrometer setting. If a Morse pyrometer is used the value of $\lambda$ for the red screen may be computed by methods described elsewhere ${ }^{2}$ from the spectral transmission of the screen and the observer's visibility curve. The transmission and the value of $\lambda$ are sufficient to determine $t$.

For precise work in optical pyrometry, the only absorption devices whose transmission can be determined with sufficient accuracy are either rotating sector disks or absorption glasses whose effective transmission has been accurately compared with that of sector disks. In either case the determination of the ratio of brightness in the formula (2) rests upon a geometrical measurement of the angular opening of a sector disk. For small angular openings of the order of $1^{\circ}$ or less, the percentage error in determining the transmission is significant.

While the definition of the temperature scale requires a measurement of the ratio of brightness $R$ in a primary temperature measurement, it is not necessary that this ratio be determined in one step. Suppose the intensity of a black body whose temperature $t$ is to be determined is $J$, that of a black body at the gold point is $J_{1}$, and that of a black body at an intermediate temperature $t_{m}$ is $J_{m}$. We may determine separately the ratios $\frac{J}{J_{m}}$ and $\frac{J_{m}}{J_{1}}$, without resorting to sectors of very small angular openings. Two sector disks are used whose transmissions are approximately equal to these ratios or one will serve if these ratios themselves are not very different.

$\Lambda$ fter the values of current for the pyrometer lamp have been determined for the gold point and for the temperature $t_{m}$ through the appropriate sector, the current value is then determined for the temperature $t_{m}$ with the sector removed. The pyrometer is then sighted upon the black body at temperature $t$ through the other

2 Fairchild, Hoover, and Peters, B. S. Jour. Research, 2 (RP65), p. 930, 1929. 
sector which will produce a brightness match with the lamp operating at the intermediate temperature $t_{m}$.

Then

Adding

$$
\begin{aligned}
& \frac{1}{1,336}-\frac{1}{t_{m}+273}=\frac{\lambda \log _{e} \frac{J_{m}}{J_{1}}}{1.432}=A_{1} \\
& \frac{1}{t_{m}+273}-\frac{1}{t+273}=\frac{\lambda^{\prime} \log _{\epsilon} \frac{J}{J_{m}}}{1.432}=A_{2}
\end{aligned}
$$

$$
\frac{1}{1,336}-\frac{1}{t+273}=A_{1}+A_{2}
$$

The values of $\lambda$ and $\lambda^{\prime}$ will differ slightly but can easily be computed as previously stated.

In sighting into a black body through a sector disk, it is necessary for accurate work to use a disk of fixed opening, which can be accurately measured on a circular dividing engine because sector disks of adjustable opening can not be made accurately enough. Therefore, since a sector must be made before the proper opening is known exactly, it can not be expected to produce a match when the lamp is operating exactly at the gold point, and the pyrometer lamp, in actual practice, must be operated at some neighboring temperature, say $t_{0}$, to secure a match. The working equation then becomes

$$
\frac{1}{t+273}=\frac{1}{t_{0}+273}+\frac{\lambda \log _{\epsilon} T}{1.432}
$$

where $T$ is $\frac{1}{360}$ of the angular opening of the sector in degrees. The value of $t_{0}$ may be obtained from the current-temperature relation ${ }^{3}$ for the lamp and, if it does not differ very much from $1,063^{\circ} \mathrm{C}$., can usually be determined to $0.1^{\circ}$ or $0.2^{\circ} \mathrm{C}$.

Since the light of wave length $0.65 \mu$ given out by a black body in the neighborhood of the gold point varies approximately as the seventeenth power of the absolute temperature, the angular openings of the sector disks used in optical pyrometry are small, usually a few degrees or less. As an illustration, Table 1 shows the angular opening and corresponding per cent transmission of sector disks that will permit measurement of various temperatures first, when the lamp is operated at the gold point and second, when the lamp is operated at some higher temperature, such as the nickel point. The nickel point has been taken as $1,455^{\circ} \mathrm{C}$. and $\lambda$ as $0.65 \mu$, approximately the effective wave length of the types of red screen usually used.

3 The methods for determining this relation are fairly obvious and will not be discussed further. 
TABLE 1.-Temperatures measurable with various sector disk openings using two fixed points

\begin{tabular}{|c|c|c|c|}
\hline \multicolumn{2}{|c|}{ Sector disk opening } & \multicolumn{2}{|c|}{$\begin{array}{c}\text { Temperature to be } \\
\text { measured }\end{array}$} \\
\cline { 1 - 2 } $\begin{array}{c}\text { Trans- } \\
\text { mission }\end{array}$ & Angle & Lamp at & Lamp at \\
& & $1,063^{\circ}$ C. & $1,455^{\circ} C$. \\
\hline Per cent & $\circ$ & ${ }^{\circ}$ C. & ${ }^{\circ} C$. \\
50 & 180.0 & 1,119 & 1,550 \\
20 & 72.0 & 1,208 & 1,705 \\
10 & 36.0 & 1,280 & 1,836 \\
5 & 18.0 & 1,360 & 1,986 \\
2 & 7.2 & 1,476 & 2,215 \\
1 & 3.6 & 1,581 & 2,432 \\
$1 / 2$ & 1.8 & 1,686 & 2,684 \\
$1 / 4$ & 0.9 & 1,825 & 2,987 \\
\hline
\end{tabular}

A glance at the table will show that if a primary measurement is to be made of a temperature above $1,800^{\circ} \mathrm{C}$., a sector of opening less

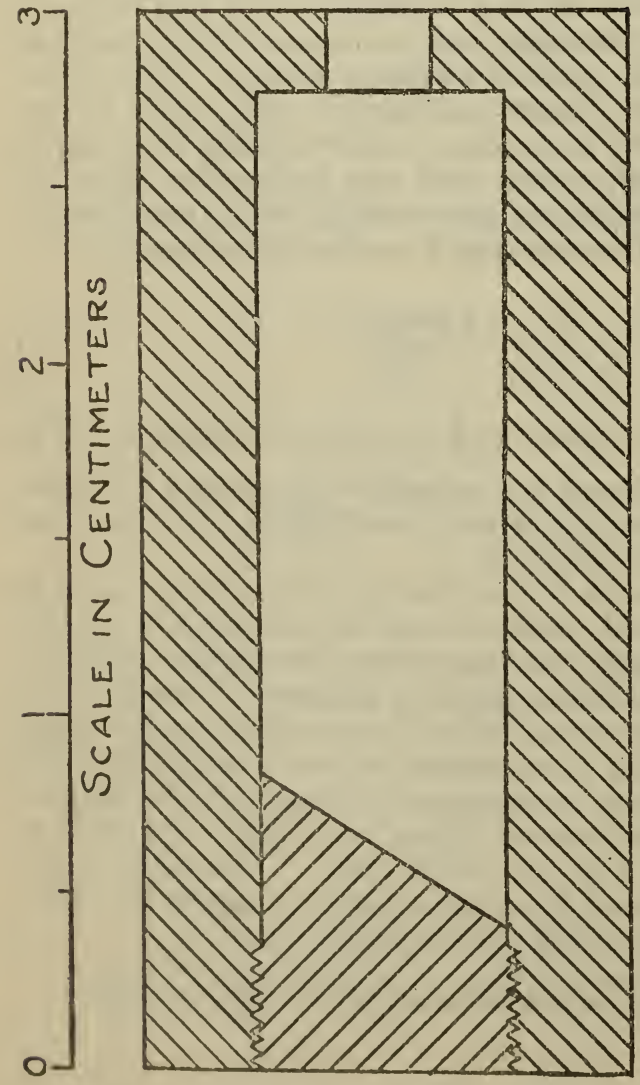

FIsUUE 1.-Cylindrical platinum black body for use in electrically heated furnace

both with and without the sector, are than $1^{\circ}$ must be used or the pyrometer lamp must be operated above the gold point. It is not practicable to use openings of this size, since the uncertainty in their measurement can not easily be reduced below 20 seconds of arc or about one-half of 1 per cent for a $1^{\circ}$ sector.

For some years the practice at the National Bureau of Standards has been to use, for securing the intermediate temperature, a platinum cylinder of the form shown in Figure 1, heated in a platinum-wound furnace. The thermal conductivity of platinum is great enough to insure a fairly high degree of temperature uniformity in the cylinder and by the use of storage batteries for supplying power to the furnace, the temperature may be kept constant except for a slight drift. It would be far better, however, to use a fixed point and make observations on a black body immersed in a freezing metal. A fixed pointwould insure that the observations, of the same brightness. 
the ratio of brightness from the fixed point used to the gold point can be determined once for all if a really satisfactory point can

The upper limit above which a pyrometer lamp should not be operated is determined largely by the changes which take place in the current-temperature relation with continued use at high temperatures. It is, of course, possible to determine and take account of these changes, but when the drift is not very slow, this work becomes both laborious and doubtful.

An inventory of the metals whose freezing points lio within the usual range of operation of pyrometer lamps shows a scarcity of metals which are readily available in a state of purity satisfactory for use as fixed points. The palladium point, which has been recently determined ${ }^{4}$ as $1,554^{\circ}$ within $2^{\circ}$ and probably within $1^{\circ}$ on the International Temperature Scale, is unfortunately. somewhat above this range. The copper point is too near the gold point to offer any advantages. Nickel is unique in being the only promising metal with a freezing point in the usable temperature range and also provides a fixed point near the upper limit of this range so that its use extends the range of temperatures measurable in this manner as far as practicable.

The present work was undertaken not only to obtain a more accurate value of the freezing point of nickel, but also to investigate the suitability of this point as a base from which to determine temperatures beyond the reach of the optical pyrometer when using only sector disks and a lamp operated near the gold point.

\section{PREVIOUS WORK}

Between 1895 and 1905 a number of values for the melting point of nickel were reported as shown in Table 2 . These values were all determined by the use of thermocouples which had been calibrated at a number of points and for which an equation was deduced for the e. $\mathrm{m}$. f. temperature relation. The values in Table 2 are of historical interest only. Curiously enough the mean of the four values given, $1,450^{\circ} \mathrm{C}$. is not very different from the values obtained in later work.

$\mathrm{T}_{\mathrm{ABLE}}$ 2.-Early observations on the melting point of nickel

\begin{tabular}{|c|c|c|c|}
\hline Observers & Year & $\begin{array}{c}\text { Purity of } \\
\text { nickel }\end{array}$ & $\begin{array}{c}\text { Melting } \\
\text { point }\end{array}$ \\
\hline $\begin{array}{l}\text { Holborn and Wien }{ }^{1} \\
\text { IGarker }{ }^{2} \\
\text { Guertler and Tamman }{ }^{3} \\
\text { Copaux }\end{array}$ & $\begin{array}{l}1895 \\
1905 \\
1905 \\
1005\end{array}$ & $\begin{array}{r}0.996 \\
.977 \\
\end{array}$ & $\begin{array}{l}{ }^{\circ} C . \\
1,474 \\
1,427 \\
1,419 \\
1,470\end{array}$ \\
\hline
\end{tabular}

1 Holborn and Wien Wied., Ann., 56, p. 360; 1895.

2 J. A. Harker, Roy. Soc. Proc. Ser., A 76, p. 235; 1905.

3 W. Guertler and G. Tamman, Zeits. f. A norg. Chem., 45, p. 205; 1905.

4 H. Copaux, C. R., 110 p. 657; 1905.

In 1907 Burgess, ${ }^{5}$ using an optical micropyrometer, determined the melting point of small bits of nickel in contact with an electrically heated platinum strip. He obtained $1,435^{\circ} \mathrm{C}$. on an optical scale of 
gold $=1,064^{\circ}$ and platinum $=1,753^{\circ}$. From the work of Hoffmann ${ }^{6}$ and from unpublished work done at the National Bureau of Standards it is known that the scale used by Burgess is about $20^{\circ}$ lower at the platinum point than the present International Scale and would probably be some $10^{\circ}$ lower at the nickel point.

In 1911 Day and Sosman ${ }^{7}$ obtained the value, $1,452.3^{\circ} \mathrm{C}$. with a nitrogen constant-volume gas thermometer. This value, rounded to 1,452 has been, with very good reason, the generally accepted value. However, since this value is based almost entirely upon one investigation in which the scale employed was not defined in the same manner as the present scale, it seemed highly desirable that this important fixed point be accurately determined on the present International Scale. As is indicated in Table 5 , the values obtained by Day and Sosman for the gold, palladium, and platinum points are all somewhat lower than these fixed points on the present scale.

\section{PURITY OF NICKEL}

The nickel used in the present work was from a special preparation of electrolytic nickel made by the International Nickel Co. This material was further purified at the National Bureau of Standards by removal of carbon and sulphur as described by Jordan and Swanger elsewhere in this journal. ${ }^{8}$ In our work two separate ingots were used having the chemical analyses shown in Table 3.

TABLE 3.-Chemical analyses ${ }^{1}$ of nickel previous to use in freezing-point determinations

\begin{tabular}{|c|c|c|}
\hline & Ingot $N-19$ & Ingot N-23 \\
\hline $\begin{array}{l}\mathrm{C} \\
\mathrm{Mn} \\
\mathrm{P} \\
\mathrm{S} \\
\mathrm{Si} \\
\mathrm{Fe} \\
\mathrm{Cu} \\
\mathrm{Co} \\
\mathrm{Mg} \\
\mathrm{Ni}\end{array}$ & $\begin{array}{c}\text { Per cent } \\
(2) \\
(2) \\
(2) \\
(2) \\
0.004 \\
(2) \\
.024 \\
.016 \\
.016 \\
.003 \\
399.94\end{array}$ & $\begin{array}{c}\text { Per cent } \\
0.005 \\
(2) \\
(2) \\
.004 \\
.006 \\
.03 \\
.006 \\
.016 \\
(2) \\
499.94\end{array}$ \\
\hline Total_ & 100.003 & 100.007 \\
\hline
\end{tabular}

1. Analyses by J. A. Scherrer and C. P. Larabee, of the chemistry division.
Not detected.

Difference.

- Direct determination.

The two ingots were also analyzed for gases before and after the freezing point determinations, the quantities found being listed in Table 4.

- Fr. Hoftmann, Zs. f. Phys., 27, p. 285; 1924.

7. L. Day and R. B. Sosman, Carnegie Inst. of Wash. Pub. No. 157, p. 107; 1911.

8. L. Jordan and W. H. Swanger, B. S. Jour. Research, 5 (RP257), p. 1291; 1930. 
TABLE 4.-Analyses ${ }^{1}$ of nickel for gases before and after use in freezing-point determinations

\begin{tabular}{|c|c|c|c|c|}
\hline \multirow{2}{*}{ Gas } & \multicolumn{2}{|c|}{ lngot N-19 } & \multicolumn{2}{|c|}{ Ingot $N-23$} \\
\hline & Before & After & Beforo & After \\
\hline $\begin{array}{l}\mathrm{O}_{2} \\
\mathrm{~N}_{2} \\
\mathrm{H}_{2}\end{array}$ & $\begin{array}{c}\text { Per cent } \\
0.001 \\
\left(^{(2)}\right. \\
<.0002\end{array}$ & $\begin{array}{c}\text { Per cent } \\
0.008 \\
\left(^{(2)}\right. \\
<.0002\end{array}$ & $\begin{array}{c}\text { Per cent } \\
0.001 \\
\left(^{(2)}\right. \\
<.0002\end{array}$ & $\begin{array}{c}\text { Per cent } \\
0.015 \\
.004 \\
<.0002\end{array}$ \\
\hline
\end{tabular}

1 Analyses by H. C. Vacher of the metallurgy division.

2 Not detected.

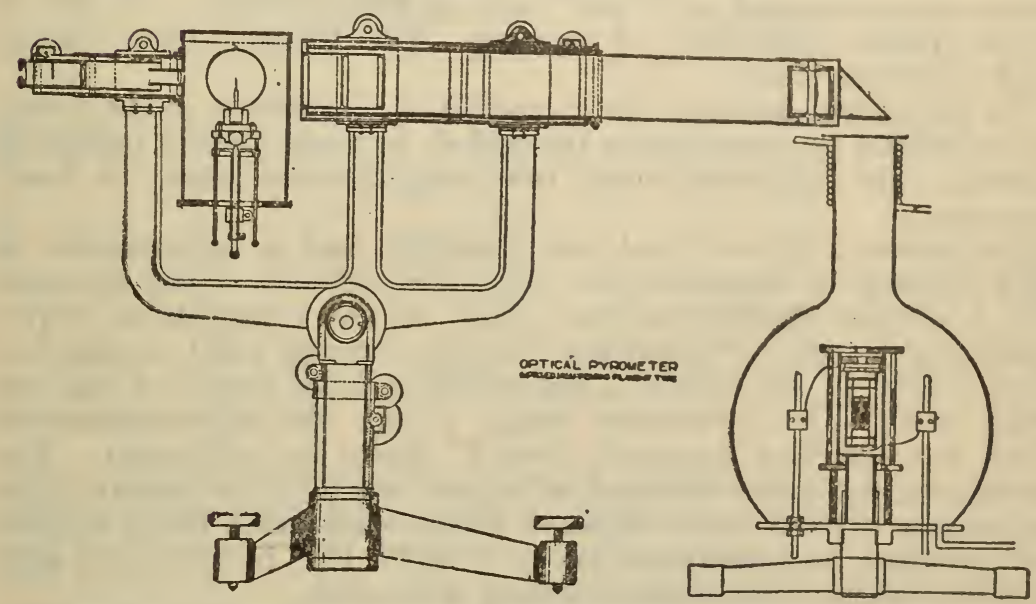

Figdre 2.-Arrangement of optical pyrometer, furnace, and crucible of metal.

Since ingot N-23 apparently picked up over twice as much gas as did ingot $\mathrm{N}-19$ without any resulting difference in the freezing point, it is concluded that the dissolved gases present had no appreciable effect.

The average temperature coefficient of resistance, for the interval $0^{\circ}$ to $100^{\circ} \mathrm{C}$. was found to be 0.00667 for the material before and 0.00672 for samples taken from the ingots after use in the freezingpoint work. The samples giving the value 0.00667 were from the same lots, but not the actual material used, while the value 0.00672 was obtained on material taken from the ingots. The difference is considered not significant.

The unusually high temperature coefficient and the chemical analyses indicate that the nickel of the two ingots $N-19$ and $N-23$ was of purity as high as any nickel that has ever been produced.

\section{EXPERIMENTAL WORK AND RESULTS}

The arrangement of optical pyrometer and melting furnace is shown in Figure 2, except that a pyrometer lamp with optically flat windows was used. The gold point was determined by sighting into a graphite tube immersed in a crucible of gold. The furnaco was $18296^{\circ}-30-9$ 
contained in a 6-liter pyrex flask which was evacuated with a mercury diffusion pump to a pressure of about $0.001 \mathrm{~mm}$ of mercury. The pyrometer telescope was equipped with a $45^{\circ}$ total reflecting prism for convenience in making observations.

The same arrangement was used in the observations on the crucibles of nickel, except that a sector disk was rotated in the space between the prism and furnace window. The same prism and furnace window were used in the observations on gold and nickel, so that the light absorbed by these optical parts need not be determined.

The furnace used for melting the gold was wound with platinum ribbon and the one used for melting the nickel was wound with an alloy wire of 20 per cent rhodium- 80 per cent platinum. The nickel furnace was provided with end coils on both bottom and top to secure greater uniformity of heating. The furnace tube was of fused zirconium oxide.

The nickel was contained in a crucible of magnesium oxide, which was found not to contaminate the nickel, by more than a negligible amount. The immersed sight tube was likewise made of fused magnesia.

The sector disk used had two openings and a transmission of 2.629 per cent as computed from the measurement of the openings with a circular dividing engine. The sector transmission corresponded to the ratio of brightness from the freezing point of nickel to about $1,070^{\circ} \mathrm{C}$. for $0.6533 \mu$, the effective wave length of the red screen used. The pyrometer lamp, during the observations on nickel, was, therefore, operated about $7^{\circ}$ above the gold point. The average current value obtained with gold was 0.11522 ampere while the average current value obtained with nickel was 0.11625 ampere corresponding to a temperature of $1,069.7^{\circ} \mathrm{C}$. In this work only the observations taken during freezing were used.

The calculation for the freezing point, $t$, is made from equation (6). If logarithms to the base 10 are used and the effective wave length is expressed in microns, this equation becomes

whence

$$
\begin{gathered}
\frac{1}{t+273}=\frac{1}{t_{0}+273}+\frac{\lambda \log _{10} T}{6,219} \\
t=1,069.7^{\circ} \mathrm{C} . \\
\lambda=0.6533 \mu \\
T=0.02629 .
\end{gathered}
$$

$$
t=1,454.8^{\circ} \mathrm{C} \text {. }
$$

The ratio of brightness, nickel to gold, for the above wave length, may be calculated from equation (2) to be 41.28 , the reciprocal of which is 0.02422 .

The order of observation was as follows:

1. Five freezes on gold.

2. Nine freezes on nickel, ingot $N-19$.

3. Four freezes on gold.

4. Six freezes on nickel, ingot $\mathrm{N}-23$.

5. Four freezes on gold.

6. Five freezes on nickel, ingot $\mathrm{N}-23$.

7. Five freezes on gold. 
The observations at the freezing point of gold indicated that no detectable drift occurred in the pyrometer lamp during the period covered by the above work. The average current through the lamp for the first nine gold freezes differed from that for the last nine freezes by only 1 part in 11,000, corresponding to a difference in temperature of less than $0.1^{\circ} \mathrm{C}$.

The results obtained on the individual freezes are listed in Table 5.

TABLE 5.-Determinations of the freezing point of nickel

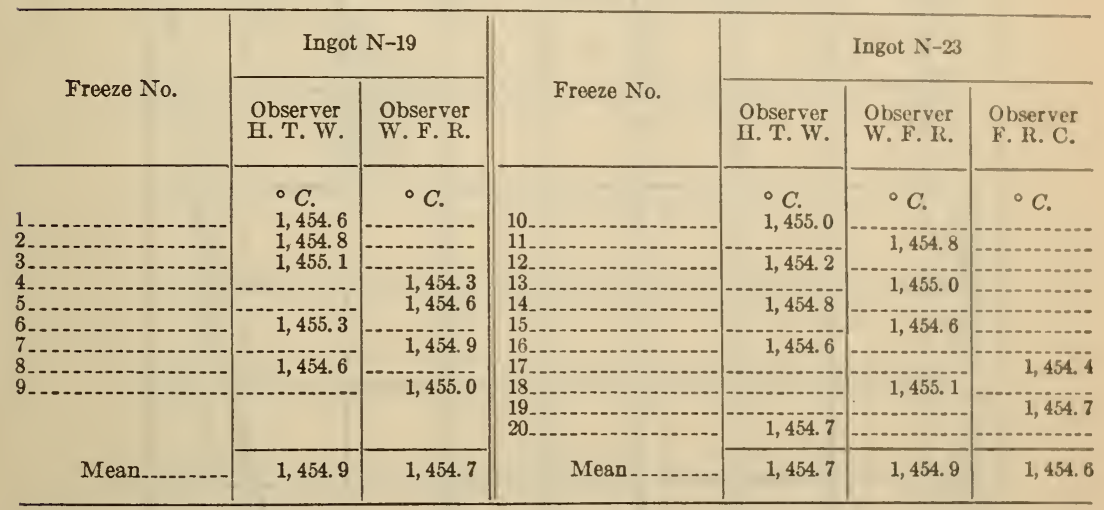

Mean of 20 freezes, $1,454.8^{\circ} \mathrm{C}$.

In comparing the result obtained with that of Day and Sosman, consideration should be given to differences in the temperature scales employed. The values given in Table 6 and plotted in Figure 3 are significant as indicating a systematic difference between their scale and the International Scale adopted in 1927.

TABLE 6.-Differences between International Temperature Scale and the scale of Day and Sosman

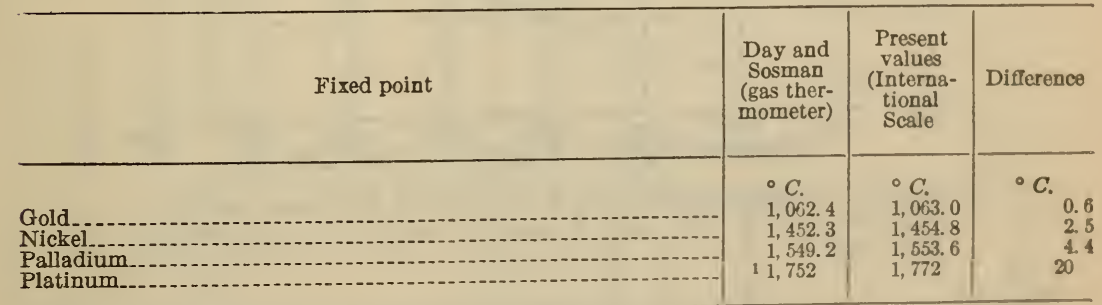

1 By extrapolation of the thermocouple calibrated at lower points against gas thermometer.

\section{DISCUSSION}

The behavior of the nickel used in the present work and the agreement between the values obtained with two separate ingots indicate that the freezing point of nickel of high purity is very satisfactory for use as a fixed point from which to start in measuring temperatures above the platinum point where the brightness relative to that of $\Omega$ black body at the gold point can not well be measured in one step with a sector disk. It is advisable to determine the freezing point of 
the particular lot of nickel so used, this freezing point serving merely to provide a steady, uniform, and reproducible temperature. The freezing should be done in an evacuated space at pressures of not more than $0.01 \mathrm{~mm}$ of mercury.

There was no evidence of appreciable contamination of the metal by the crucibles of magnesium oxide. No decrease in the temperature coefficient of resistance took place nor did the freezing point show any drift with successive melts and freezes.

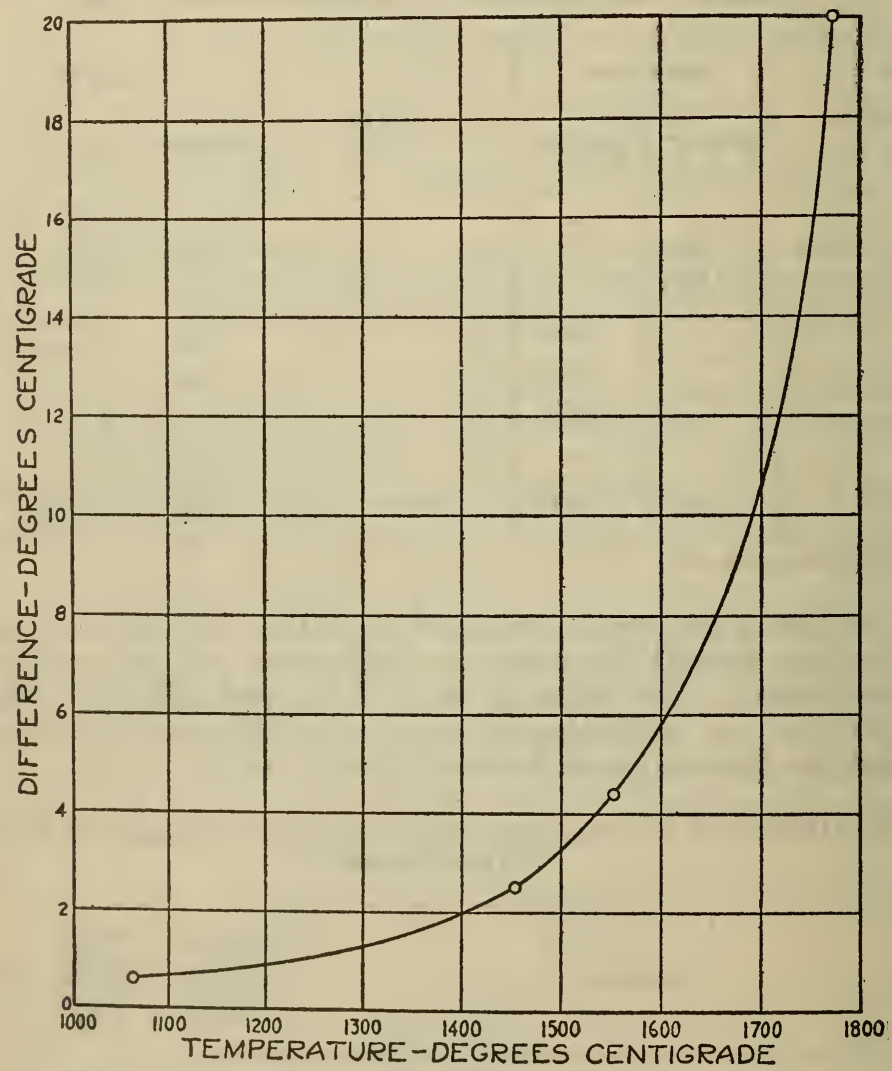

FIGURE 3.-Differences between International Temperature Scale and the scale of Day and Sosman as obtained from data on fixed points

The freezing point of the nickel used is probably slightly lower than that for the absolutely pure metal, but calculation indicates the maximum difference to be less than $1^{\circ}$. Very likely this difference is not over $0.5^{\circ} \mathrm{C}$. For this reason we have considered it advisable to round our result from $1,454.8^{\circ}$ to $1,455^{\circ} \mathrm{C}$. On the International Seale, which is based on the value $1,063^{\circ} \mathrm{C}$. for the freezing point of gold and the value $1.432 \mathrm{~cm} \mathrm{deg}$. for $\mathrm{C}_{2}$. The value $1,455^{\circ} \mathrm{C}$. here obtrined is believed to be within $1^{\circ}$ on the present scale of the true value either for pure nickel or the nickel actually used.

Wasingaton, July 16, 1930. 